\title{
Diabetes como factor de riesgo de Periodontitis
}

\author{
Antonio José López Garvía, Antonia Molina Escribano ${ }^{b}$, \\ María Cruz Ramírez García ${ }^{c}$, María José Aparicio Mínguez ${ }^{d}$
}

\begin{abstract}
a Odontólogo de la Unidad de Salud Bucodental Almansa I (Albacete).

Centro de Salud de Almansa (Albacete).

b Odontólogo de la Unidad de Salud Bucodental Albacete.
\end{abstract}

${ }^{c}$ Higienista dental de la Unidad de Salud Bucodental Albacete.

${ }^{d}$ Higienista dental de la Unidad de Salud Bucodental Almansa (Albacete).

\section{Correspondencia:}

Antonio José López Garví. Centro de Salud Almansa, C/ S.Juan s/n, 02640-Almansa (Albacete).

E-mail: ajlopezg@sescam.jccm.es. Tfno.: 696614451.

Recibido el 12 de septiembre de 2007.

Aceptado para su publicación el 28 de septiembre de 2007.

\section{RESUMEN}

La periodontitis en una enfermedad de etiología infecciosa que presenta como síntomas el sangrado de encías, movilidad del diente, recesiones gingivales o hipersensibilidad dentaria, y en la que diversas enfermedades sistémicas pueden favorecer su progresión, entre ellas la diabetes mellitus. Se presenta el caso de un varón que acude a consulta por sangrado e inflamación de encías, que presenta un historial de diabetes insulinodependiente de 35 años de evolución. El paciente es diagnosticado de una periodontitis generalizada en fase moderada, aunque algunas piezas dentales presentan un estado avanzado con pérdida de cresta alveolar superior al $50 \%$. El plan de tratamiento incluye: instrucción en higiene oral, raspados y alisados radiculares de todos los dientes, cirugías periodontales y mantenimiento periodontal periódico. Dada la importancia de la detección precoz de la periodontitis, el médico de familia juega un papel muy importante a la hora de derivar a estos pacientes al dentista para su diagnóstico y control.

Palabras clave. Periodontitis. Diabetes Mellitus.

\section{ABSTRACT}

Diabetes as a risk factor for Perodontitis.

Periodontitis is an infection which causes symptoms such as bleeding gums, loose or separating teeth and receding or tender gums. It can also advance the progression of some diseases amongst them diabetes mellitus. We report a case of a man who came to the doctor's consultancy due to bleeding, swollen gums. He had had insulin dependent diabetes for the last 35 years. The patient was diagnosed with generalised, moderate periodontitis, although some teeth were at an advanced stage with over $50 \%$ loss of the alveolar crest. Treatment included: instruction in oral hygiene, scaling and root planing of all teeth, periodontal surgery and periodic periodontal check ups. Early detection of periodontitis is very important and the family doctor can play a very important role in referring these patients to the dentist for diagnosis and control.

Key Words. Periodontitis. Diabetes Mellitus.

\section{INTRODUCCIÓN}

La periodontitis o piorrea es una enfermedad infecciosa que aparece como una reacción inflamatoria de la encía a la placa bacteriana. Esa inflamación en los tejidos gingivales es la respuesta de los mismos a las bacterias presentes en la placa dental. Inicialmente, la placa dental produce una reacción inflamatoria gingival que es reversible porque no ha producido destrucción del tejido. Esta reacción se conoce como gingivitis. Pero en algunos individuos, si no existe un tratamiento previo de remoción de placa que elimine esa gingivitis, la reacción inflamatoria continúa y al final acaba produciendo una destrucción de tejidos periodontales, como el ligamento periodontal y cresta del hueso alveolar. Esta lesión se conoce como periodontitis y se caracteriza por ser irreversible. Según la pérdida ósea, la periodontitis se clasifica cono inicial (pérdida de la cresta ósea inferior al $20 \%$ de la longitud de la raíz dentaria), moderada (pérdida ósea superior al $20 \%$ e inferior al $50 \%$ ) y avanzada (pérdida ósea superior al $50 \%$ ), siendo en esta última fase cuando el diente presenta movilidad importante y su pronóstico es malo, estando indicada en muchas ocasiones la extracción dental. Sus síntomas son el sangrado de encías, recesiones gingivales, movilidad del diente o hipersensibilidad dentaria a estímulos como el calor o el frío. 
Por otra parte, es necesaria para el desarrollo y progresión de la periodontitis una predisposición individual o una mayor susceptibilidad del huésped, la cual puede venir determinada por diversos factores como la predisposición genética, el consumo de tabaco, y ciertas enfermedades sistémicas como la diabetes y la osteoporosis. La mayoría de los autores consideran a la diabetes mellitus, tanto insulinodependiente como no insulinodependiente, como una enfermedad sistémica que favorece la progresión de la periodontitis ${ }^{1-4}$. Actualmente, se piensa que la angiopatía, así como la inhibición de la actividad de neutrófilos y macrófagos $^{1}$, podrían estar entre las causas que favorecen la instauración y progresión de la periodontitis en este tipo de pacientes. Asimismo, se ha visto en numerosos estudios que la diabetes mal controlada favorece la progresión de la enfermedad, y que un adecuado tratamiento y control de la enfermedad periodontal ayudaría al control de la diabetes ${ }^{2}$.

\section{OBSERVACIONES CLÍNICAS}

A continuación presentamos el caso de un varón de 45 años, que acude a la consulta porque presenta inflamación y sangrado de encías. Respecto a su historial médico, se trata de un paciente no fumador, que fue diagnosticado de diabetes mellitus tipo 1 a los 10 años de edad, y que actualmente es tratado con insulina. Aunque en el momento presente el paciente

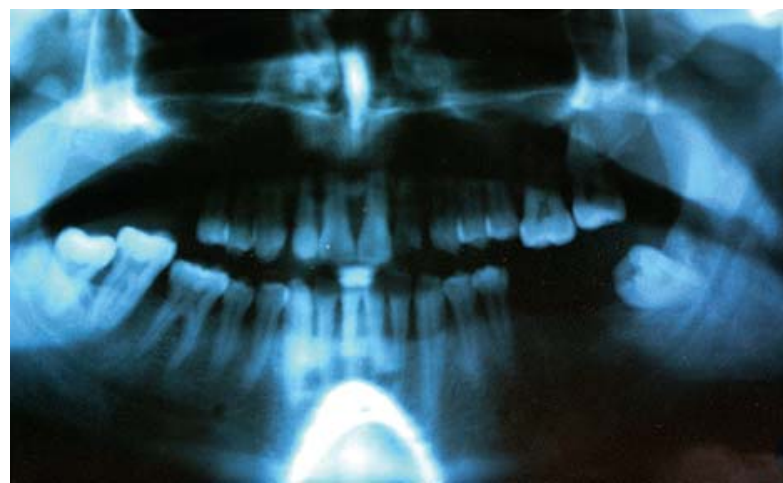

Figura 1. Ortopantomografía. presenta un buen control de la diabetes, durante los dos últimos años estuvo mal controlada. El paciente no toma ninguna otra medicación y no presenta ningún otro antecedente personal de interés. Respecto a sus antecedentes familiares, no existe historial de periodontitis en ningún miembro de su familia. A la exploración, el paciente presentaba inflamación gingival con sangrado de encías, hipersensibilidad dentinaria, recesiones gingivales, movilidad dentaria, y ausencia de piezas dentarias que el paciente se extrajo con anterioridad como consecuencia de la movilidad que presentaban debido a una periodontitis avanzada. La higiene bucal era buena y, aunque se detectó la presencia de sarro supragingival y subgingival, éste no era excesivo. La periodicidad de asistencia al dentista era bianual. Se le realizó un estudio radiográfico bucal completo que incluía una ortopantomografía y una serie radiográfica intraoral a base de radiografías periapicales. Radiológicamente presentaba una pérdida de la cresta del hueso alveolar de forma generalizada, con un patrón de pérdida ósea con defectos verticales, siendo del $40 \%$ de la longitud radicular a nivel de los dientes anterosuperiores y anteroinferiores, y del 70 al $80 \%$ en el primer y segundo premolares superiores derechos. Asimismo, presentaba un área quística asociada a las raíces del $1^{\circ}$ molar superior izquierdo de etiología endoperiodontal.

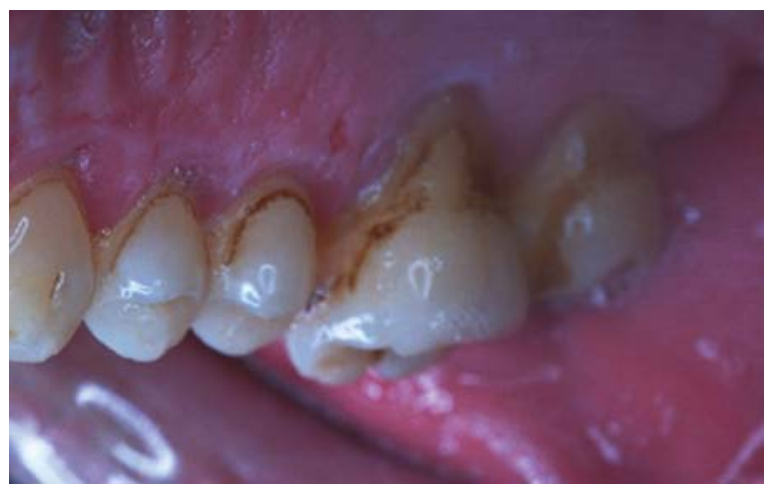

Figura 2. Recesión gingival a nivel palatino del $2^{\circ}$ molar superior derecho.

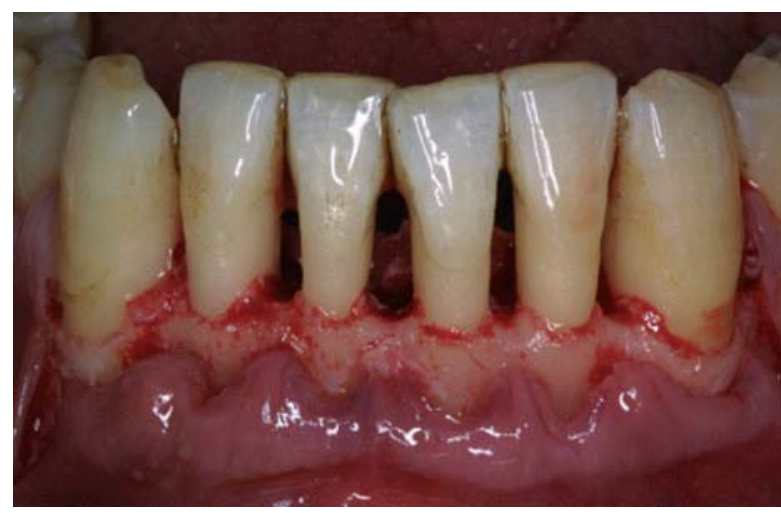

Figura 3. Detalle de la pérdida ósea a nivel de los dientes anteroinferiores durante la cirugía periodontal. 
El paciente fue diagnosticado de una periodontitis crónica en la que la diabetes es un factor sistémico que ha acelerado su progresión. Una vez realizado el diagnostico se elaboró un plan de tratamiento que incluía las siguientes fases.

1. Fase de instrucción en técnicas de higiene oral: se le instruyó en un cepillado manual meticuloso de los dientes, espacios interdentales, lengua y mucosas orales durante tres veces al día, con un cepillo de dureza media.

2. Fase desinflamatoria: se eliminó todo el sarro y la placa supragingival y subgingival mediante raspados y alisados radiculares. Se le pautó la realización de enjuagues con colutorio de clorhexidina al $0,12 \% 2$ veces al día durante 2 semanas y una profilaxis antibiótica previa a la realización de los raspados.

3. Fase quirúrgica: consistió en la realización de cirugías periodontales para la corrección de los defectos óseos.

4. Fase de mantenimiento periodontal: se citó al paciente a revisiones periódicas cada 3 meses con el fin de realizar reevaluación de su estado periodontal y la eliminación de placa y sarro. Asimismo, se le pautó la realización de enjuagues con un colutorio de clorhexidina al $0,05 \%$ de forma diaria.

\section{DISCUSIÓN}

Es numerosa la literatura científica en la que se establece a la diabetes como una enfermedad que favo- rece la progresión de la periodontitis. En este caso, se presenta de una forma clara la relación entre la diabetes y la periodontitis, sin presentar ningún otro factor, patología o hábito que pudieran estar relacionados con la periodontitis. Además, el paciente presenta una historia de diabetes mal controlada, lo cual ha sido relacionado repetidamente en la literatura con un mayor riesgo en la progresión de la periodontitis. Dado que la piorrea en fases avanzadas conduce a la pérdida dentaria con las consiguientes alteraciones de la función y estética orales, y que en las fases iniciales es más fácil su control y presenta mejor pronóstico, es importante en este tipo de pacientes su detección precoz. Los pacientes que son diagnosticados de diabetes mellitus suelen acudir frecuentemente a consulta del médico de familia y de enfermería, por lo que ambos han de jugar un papel muy importante a la hora de informar y derivar a las Unidades de Salud Bucodental para su diagnóstico y tratamiento ante cualquier sospecha o síntoma de sangrado o inflamación de encías, recesiones gingivales, movilidad o hipersensibilidad dentaria.

\section{BIBLIOGRAFÍA}

1. Bagan Sebastian JV, Ceballos Salobreña A, Bermejo Fenoll A, Aguirre Urizar JM, Peñarrocha Diago M. Medicina Oral. 1th ed. Barcelona: Masson; 1995.

2. Sociedad Española de Periodoncia y Osteointegración. Agrandamiento gingival no tumoral. Manual SEPA de Periodontcia y Terapeútica de Implantes: Fundamentos y guía práctica. 1th ed. Madrid: Ed. Panamericana; 2005.

3. Wolf H, Rateitschak E, Rateitschak K. Periodoncia. 3th ed. Barcelona: Masson; 2005

4. Bagán Sebastián JV, Vera Sempere F. Patología de la mucosa oral. 1th ed. Barcelona: Syntex latino; 1989. 